\title{
Traumatic Aneurysm
}

National Cancer Institute

\section{Source}

National Cancer Institute. Traumatic Aneurysm. NCI Thesaurus. Code C35843.

An aneurysm caused by physical injury. 